\title{
Burnishing of AM Materials to Obtain High Performance Part Surfaces
}

\author{
Michela Sanguedolce ${ }^{1}$ (D) , Giovanna Rotella ${ }^{2}$ (iD), Maria Rosaria Saffioti ${ }^{1}$ (i) Luigino Filice $^{1}$ (iD) \\ ${ }^{1}$ Department of Mechanical, Energy and Management Engineering, University of Calabria (Italy) \\ ${ }^{2}$ Department of Engineering for Innovation, University of Salento (Italy) \\ michela.sanguedolce@unical.it,giovanna.rotella@unisalento.it,mariarosaria.saffioti@unical.it,lnigino.filice@unical.it
}

Received: May 2021

Accepted: October 2021

\section{Abstract:}

Purpose: This paper aims to provide a flexible solution to include additive manufacturing into a process chain complying with Industry 4.0 pillars, overcoming major drawbacks in terms of reliability and experimental effort.

Design/methodology/approach: The study is based on the combination of real experimental activities and simulated ones.

Findings: The main findings of this work consist into validation of the proposed process chain, which proves to be effective in terms of process flexibility (additive manufacturing, burnishing and process simulation acting synergistically), cost and time reduction and final output quality, encouraging customer involvement towards customization.

Originality/value: This paper contributes to current research on the application of burnishing process, an easy to implement and environmentally friendly post-processing method to improve the performance of AM products, by providing a unique perspective integrating a reliable simulation model. Other researchers can employ these outcomes towards manufacturing of the future. A reduced version of this work has been previously published in Procedia Computer Science (Sanguedolce, Rotella, Saffioti \& Filice, 2021).

Keywords: smart manufacturing, burnishing, additive manufacturing, simulation, sustainability

\section{To cite this article:}

Sanguedolce, M., Rotella, G., Saffioti, M.R., \& Filice, L. (2022). Burnishing of AM materials to obtain high performance part surfaces. Journal of Industrial Engineering and Management, 15(1), xx-yy. https://doi.org/10.3926/jiem.3608

\section{Introduction}

The advent of the digital transformation process, as an integral part of Industry 4.0 context, is providing to manufacturers the possibility to reach a perfect balance between product personalization, process flexibility and competitiveness on the market. The evolution of industrial manufacturing has undergone continuous changes over time. A series of different paradigms have occurred, starting with the craft (customer) production (CP) paradigm during the first industrial revolution. It was characterized by manufacturing a small range of products at high cost 
according to user's specifications. Afterwards, in response to the necessity of standardization, the mass production (MP) was established based on large scale manufacturing systems, making low-cost goods, still with a very restricted portfolio. Thus, in order to enlarge the variety of products required by customers, the mass customization production (MCP) paradigm emerged. It provided for the exploitation of automation, information and computer technology leading to a broad gamma of products through faster and computerized processes, flexibility, high productivity and cost reduction (Wang, Ma, Yang, \& Wang, 2017). Nowadays, further changes regarding the interest of companies are taking place. They introduced the customer integration to maximize their returns, towards adopting the mass personalization production (MPP) paradigm. Consequently, as it happens for the supplier, the customers play a key role by actively participating to the production process, creating their own products in conformity with their specific needs (Koren, Shpitalni, Gu, \& Hu, 2015).

Additive Manufacturing (AM) is a fairly new technology, emerging as one of the Industry 4.0 pillars, promoting proactive flexibility strategies. This kind of production process allows great flexibility in complex shapes components production ensuring reduction of production time, costs and raw materials waste. On the other hand, the main problems arising are low surface quality and accuracy, porosity development and detrimental residual stresses into the components. As concerns the context of industry 4.0, the relevance of additive manufacturing enables shortening value chain and it allows iterative product lifecycle. By comparing the conventional process development with an iterative one, involving customer integration, an additional evaluating phase arises where the customer takes part into incremental product adjustments (Brettel, Klein \& Friederichsen, 2016).

\section{Literature Review}

In order to build 3D objects, without using conventional manufacturing $(\mathrm{CM})$, which usually involves material removal processes to achieve a desired shape, additive manufacturing (AM) technology can be employed. AM is the process of depositing and joining material, it was born as a technology to manufacture pieces to be used in the internal product development process (rapid prototyping), and currently, AM technologies are being intensively developed to meet the requirements of the industrial production. In fact, such technology suits the challenge to manufacture individualized products at an affordable cost but to effectively enable the production of a wide range of individualized products, it is necessary to integrate the AM machines into a manufacturing system containing other operations. Anyway, it is essential to ensure that the efficiency of the production is not affected by the cycle time variation (Gu \& Koren, 2018).

For a mass production of low-complexity products conventional subtractive manufacturing (SM) is still preferred, although additive manufacturing systems can ensure a cost drop when high-complexity goods need to be produced. Therefore, a comparison based only on production volumes is improper to exhaustively represent the boundary between AM and SM in terms of cost-effectiveness. In this regard, Fera Macchiaroli, Fruggiero and Lambiase (2018) presented a methodology to assess the suitability of using AM in respect of the product features, drawing a convenience diagram based on a complexity index definition.

Another aspect that stands out comparing AM with CM is the possibility to fabricate a final product in a single step. This is one of the main advantages attributed to AM processes while CM requires multiple stages and processes, implying the relocation of semi-finished product from a machine to another (Gibson, Rosen \& Stucker, 2015). However, as already previously mentioned, the reliability of the AM products can suffer from poor surface quality, porosity, anisotropy, lack of precision and accuracy, etc., consequently requiring additional post-processing and heat treatments (Abdulhameed, Al-Ahmari, Ameen \& Mian, 2019; Yang, Gong, Qu, Rong, Sun \& Cai, 2018). In fact, the above issues need to be overcome when manufacturing components for critical applications (e.g., aerospace and biomedical), involving high resistance to fatigue loads and extreme working conditions.

The benefits related to finishing processes span from improved fatigue life to higher corrosion resistance and strength enhancement. In this regard, burnishing process can successfully replace other surface finishing processes like honing, grinding and superfinishing (Delgado, Cuesta, Alegre \& Díaz, 2016; Salmi, Huuki \& Ituarte, 2017; Schulze, Bleicher, Groche Guo \& Pyun, 2016) and recent developments concern the possibility to machine complex-shaped parts (De Lacalle, Rodriguez, Lamikiz, Celaya \& Alberdi, 2011). 
The additively manufactured components can be easily mounted on CNC turning center, combining the two different processes in a hybrid manufacturing technique, consisting of $\mathrm{AM}$ and subtractive manufacturing, it is possible to overcome the AM limitations such as poor surface quality and lack of precision (Bai, Wu, Qiu, Zhang \& Chen, 2020; Yang et al., 2018).

Burnishing is severe plastic deformation (SPD) process in which does not occur a chip formation and it is able to modify the surface characteristics by uniforming roughness. More specifically, it can increase the product performance through smoothing the asperities by imposing a strong pressure on the worked surface and removing microcracks and voids resulting from previous production processes. Some studies show that hybrid machining techniques are also involving turning and burnishing processes. This new machining concept, based on the combination of processes, is able to exploit the high potential of each process providing large flexibility (Maiß, Denkena \& Grove, 2016). Furthermore, as an example, recent works discuss about burnishing of complex shaped components in force feedback control, thus keeping burnishing force constant, as it has been recognized as a major influencing process parameter with respect to surface integrity (Cao, Zhu, Tanaka, Shiou, Sawada \& Yoshioka, 2019).

Various industries, in particular those that use stainless steels (SS) are focusing on AM components and their quality become important when these alloys are employed in the field of aerospace, biomedical instruments, etc.; which often include strict working conditions, such as under high stresses and corrosive environments. The corrosion resistance of the AM components depend on the alloy microstructure characterized by the printing parameters chosen, which should be optimized according to the Industry 4.0 specifications related to product customization level required.

In this work, the material under investigation is additively manufactured GP1 stainless steel involved into the marine field due to the presence of combined martensite and austenite microstructure (Rotella, Filice \& Micari, 2020). Then, burnishing has been selected as a proper post-process capable to fit the Smart Manufacturing pillars. An experimental campaign was carried out in order to evaluate the capability of the process to improve surface integrity and high cycle fatigue life of additively manufactured samples, obtained by laser powder bed fusion process (L-PBF), where a laser selectively melts metal powder located within a powder bed, delivered on a substrate plate by means of a roller. Furthermore, a finite element model has been implemented in order to describe the process and predict its influence on the overall product quality. Such methodology successfully replaces additional expensive tests representing a further pillar of Industry 4.0. In fact, with reference to the above-mentioned mass personalization production paradigm, process simulation allows to optimize the analysed process in terms of working parameters and lubrication, further contributing to the manufacturing of customized products at a reasonable cost and paving the way for the development of a process digital twin.

From a managerial point of view, the use of secondary operations enlarges the research space to optimize the manufacturing process. In other words, the need of special component behaviour requires a redesign of the manufacturing sequence. Flexibility, in this case, is suitable allowing an improved process effectiveness, which can become a competitive advantage for the industry. In fact, real companies working in the manufacturing area could adopt this kind of technologies opening a new scenario with respect to the use of proper processes and machines able to manufacture ready-to-use components but at a higher cost.

A reduced version of this work has been previously published in Procedia Computer Science (Sanguedolce et al., 2021).

\section{Materials and Methods}

\subsection{Experimental Procedure}

For the experimental campaign (Rotella et al., 2020), samples have been fabricated in shapes of dog bone according to ASTM E466-15 (2002) standard, through an L-PBF process. An optimized set of parameters has been employed, conforming to the manufacturer of the printer, EOS GmbH. Figure 1 shows the experimental setup for machining and burnishing, in the specific case of burnishing. 
After removal from the sintering plate, samples in as fabricated condition (as printed - AP) have undergone a thermal treatment with the purpose of residual stress release, at $650^{\circ} \mathrm{C}$ for 1 hour. Subsequently, machining process has been performed on dog bone samples in order to remove low quality outer layers and obtain a surface finish suitable for burnishing. The following parameters have been used for machining: $100 \mathrm{~m} / \mathrm{min}$ cutting speed, $0.1 \mathrm{~mm}$ depth of cut and $0.05 \mathrm{~mm} / \mathrm{rev}$ feed rate (Rotella et al., 2020).

Burnishing has then been performed on machined samples through a commercial roller-burnishing tool, in force feedback control, using a piezoelectric dynamometer. A nozzle has been employed to deliver vegetable oil in minimum quantity lubrication (MQL) on the contact area between tool and workpiece. The parameters used for the process are reported in Table 1.

\begin{tabular}{|l|c|}
\hline \multicolumn{1}{|c|}{ Burnishing parameter } & Values \\
\hline Burnishing force $\mathrm{F}[\mathrm{N}]$ & $1000-1500-2000$ \\
\hline Burnishing speed $\mathrm{v}[\mathrm{m} / \mathrm{min}]$ & $50-100-150$ \\
\hline Burnishing feed $\mathrm{f}[\mathrm{mm} / \mathrm{rev}]$ & $0.05-0.1$ \\
\hline Tool radius $\mathrm{R}[\mathrm{mm}]$ & $2.5-5$ \\
\hline
\end{tabular}

Table 1. Burnishing process parameters employed into experimental campaign

Relating to processes involving severe plastic deformation (SPD), it has been found that MQL lubrication represents the right compromise between flood lubrication and dry processing (Rotella et al., 2020). In fact, the total absence of cooling or lubrication often represents an issue in terms of tool wear and surface integrity of the component. On the other hand, an extensive use of lubricants may result in environmental issues, especially in terms of waste disposal, and it has been found to negatively affect working environment safety, in particular because of hazardous aerosols generated.

In order to evaluate the effects of burnishing process on additively manufactured components, high cycle fatigue life has been assessed. In particular, tests have been carried out (Figure 2) following the step by step method to evaluate the fatigue limit for a specific number of cycles thus varying the applied testing stress according to sample failure, iteratively (Lanning, Nicholas \& Haritos, 2005).

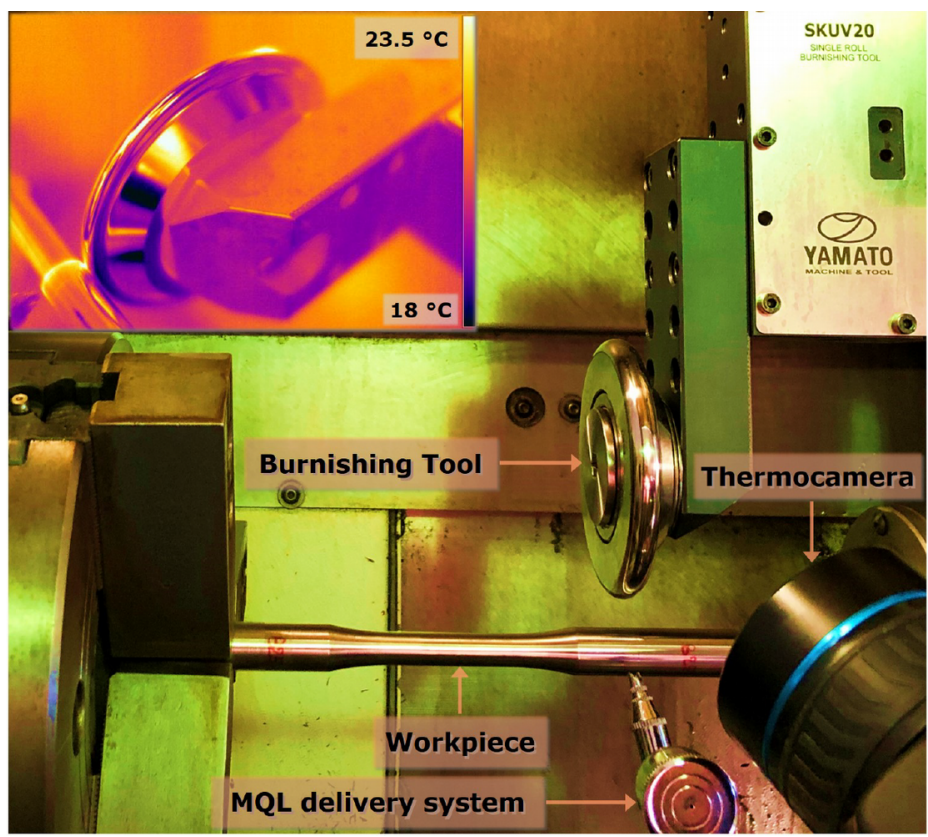

Figure 1. Experimental set-up for burnishing tests (Sanguedolce et al., 2021) 


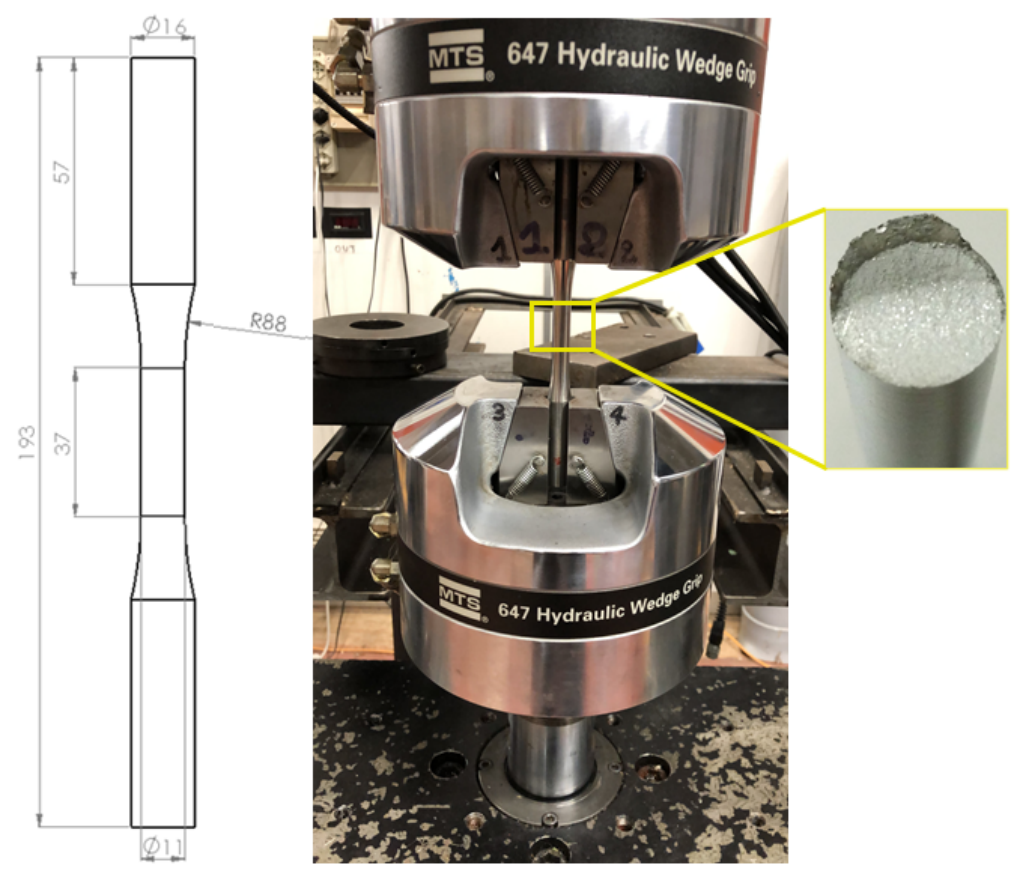

Figure 2. Fatigue sample specifications, test set-up and fracture surface (Sanguedolce et al, 2021)

\subsection{Simulations}

The SFTC DEFORMC software was employed to implement a 3D numerical simulation of roller burnishing process, of which results were compared with the ones from the experimental campaign in order to determine the effect of different burnishing conditions and parameters for real system optimization. In particular, the conditions and parameters as input of the simulation were tool characteristic dimension, burnishing force, feed rate, and number of passes (Figure 3) while the output variables in terms of post-processing quality of the product defined by the simulation were grain size, hardness, residual stresses, roughness, thickness of the affected layer etc.

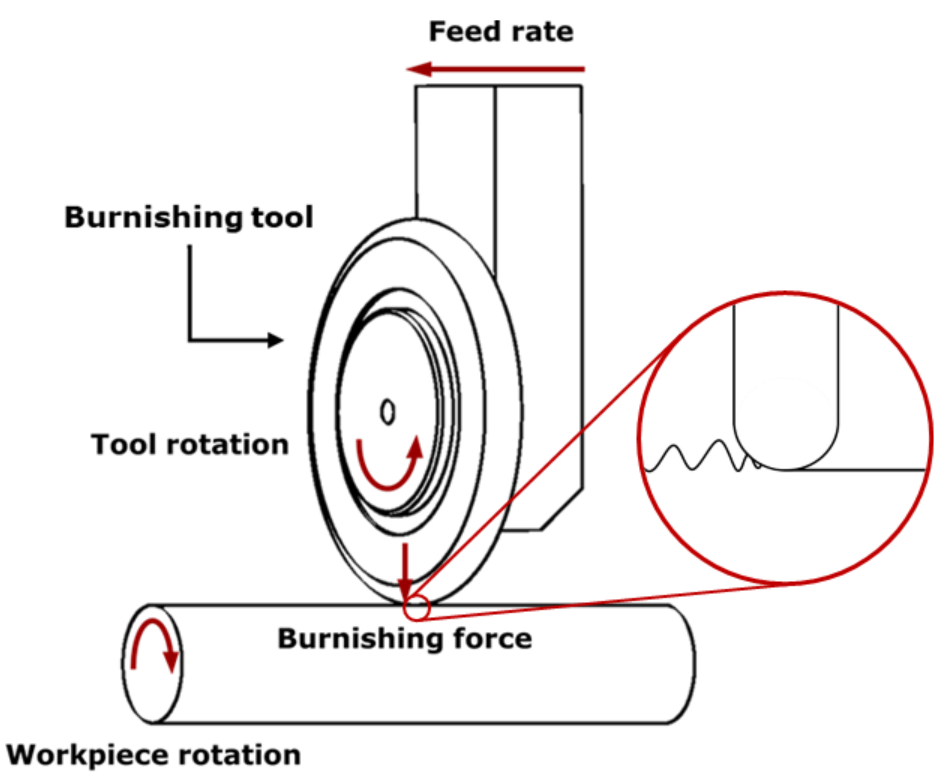

Figure 3. Scheme of roller burnishing process (Sanguedolce et al, 2021)

In order to simulate the real process a rigid tool and a plastic workpiece were built. The mesh, which includes 140,000 elements for the elasto-plastic workpiece and 40000 elements for the rigid tool is more refined in the 
contact area; mesh together with boundary and movement conditions used are shown in Figure 4. First of all, in a displacement-controlled motion, the tool was pressed into the work piece. In a second phase the workpiece was put into rotation and as result of friction it addressed the motion to the tool, allowing to reach the fixed experimental burnishing force by defining a constant corresponding depth of burnishing.

For these simulations the plastic flow data are fundamental as the flow stress governs the behavior of the objects undergoing permanent deformation. Stress required for deformation was given as a function of plastic strain, strain rate and temperature. Furthermore, through correlated equations, additional factors such as grain size or residual stresses are taken into account.

The sparse solver has been used, which takes advantage of the characteristics of the DEFORM matrix equations to solve the equations in an efficient way, especially for large problems. It was combined with a Newton-Raphson method, which tries to solve the finite element equations stating the problem by iteratively approximating to the solution until convergence is achieved.

The contact algorithm highlights, on the workpiece, which nodes are touched by the tool surface. Thus, it was important to specify the friction coefficient, which means the friction at the interface between two objects. In DEFORM the friction coefficient may be specified as a constant, a function of time, temperature, pressure, sliding velocity etc. or creating a user routine. The friction types allowed are several, according to different existing models. In the simulation developed herein, the Coulomb model was used with a coefficient of $10^{-5}$.

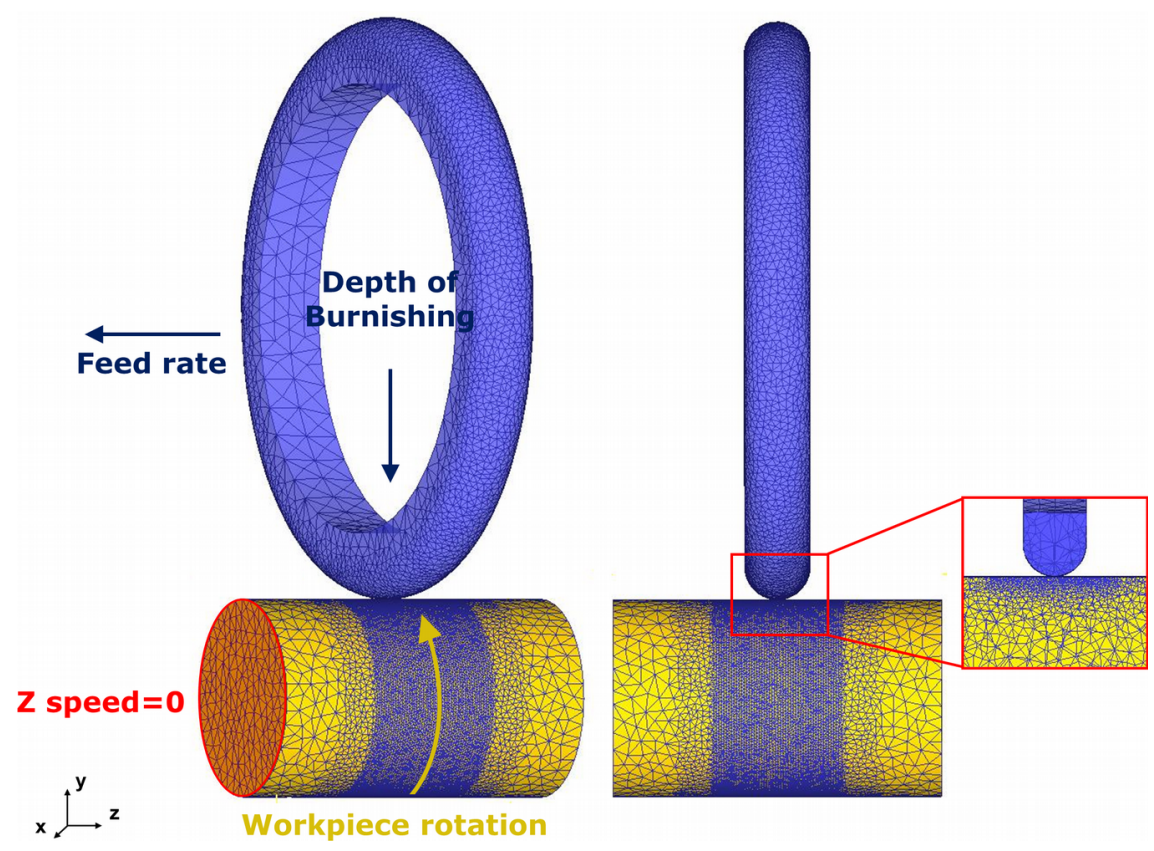

Figure 4. Numerical model movement setup, boundary conditions and mesh

(Sanguedolce et al., 2021)

As described in the flow chart shown in Figure 5, the aim of this validated simulation model is to support the decision-making process on selecting burnishing conditions, avoiding further, costly and time-consuming experimental tests, but maintaining the same reliability. Hence, the combination between simulated and real processes provides a high potential in helping the manufacturer to manage a proper planning and allowing to fulfil some special costumer needs, according to additive manufacturing principles, such as the "complexity is free" concept.

In conclusion, the numerical model is able to provide the optimized parameters by linking the technical specific requirements to the mechanical properties i.e., hardness (HIT), roughness (Ra) and residual stresses (RS), shown in Figure 5, which are the main responsible for fatigue resistance of a component. 


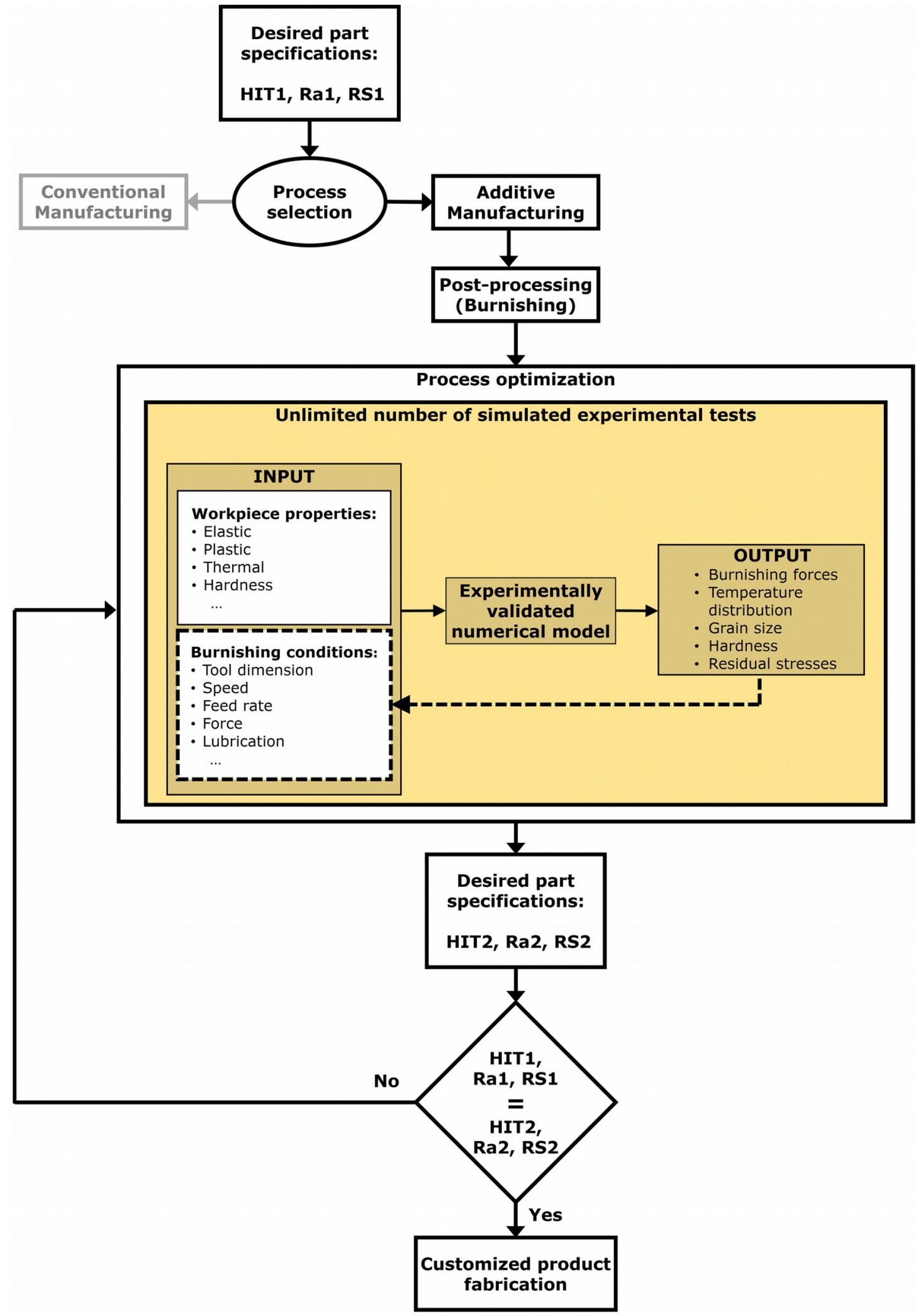

Figure 5. Process selection and optimization workflow (Sanguedolce et al, 2021)

\section{Results and Discussion}

Burnishing process brings to improvements in overall components quality, in particular concerning surface roughness, hardness, introduction of deep compressive residual stresses and reduction of porosity through plowing. Best and worst results (BR and WR, respectively) are here reported, showing that higher burnishing force, 
together with higher burnishing speed and tool radius and lower feed rate contribute in achieving superior component quality. In fact, best case scenario is given by F $2000 \mathrm{~N}, \mathrm{v} 150 \mathrm{~m} / \mathrm{min}, \mathrm{R} 5 \mathrm{~mm}$, feed rate $0.05 \mathrm{~mm} / \mathrm{rev}$ while worst case scenario was characterized by F $1000 \mathrm{~N}, \mathrm{v} 100 \mathrm{~m} / \mathrm{min}, \mathrm{R} 2.5 \mathrm{~mm}$, feed rate $0.1 \mathrm{~mm} / \mathrm{rev}$.

Figure 6 reports optical and scanning electron microscopies of mounted, polished and etched specimens, highlighting laser tracks and the scanning strategy (Figure 6b) employed for samples manufacturing as well as a sporadic presence of porosity (Figure 6d). The microstructure is a dendritic-cellular one, reaching a characteristic dimension below $1 \mu \mathrm{m}$ (Figure 6e). From the same Figure, the entity of affected layer (Figure 6f) and the reduction of surface roughness is also immediately recognizable. In as printed conditions, mean surface roughness Ra measured along sample longitudinal direction amounts to $11 \mu \mathrm{m}$ while, after machining, a value of $0.45 \mu \mathrm{m}$ has been reached. An up to $62 \%$ decrease in $\mathrm{Ra}$ has been introduced moving from the sole machining to the combination of machining and burnishing, reaching a minimum value of Ra equal to $0.17 \mu \mathrm{m}$.
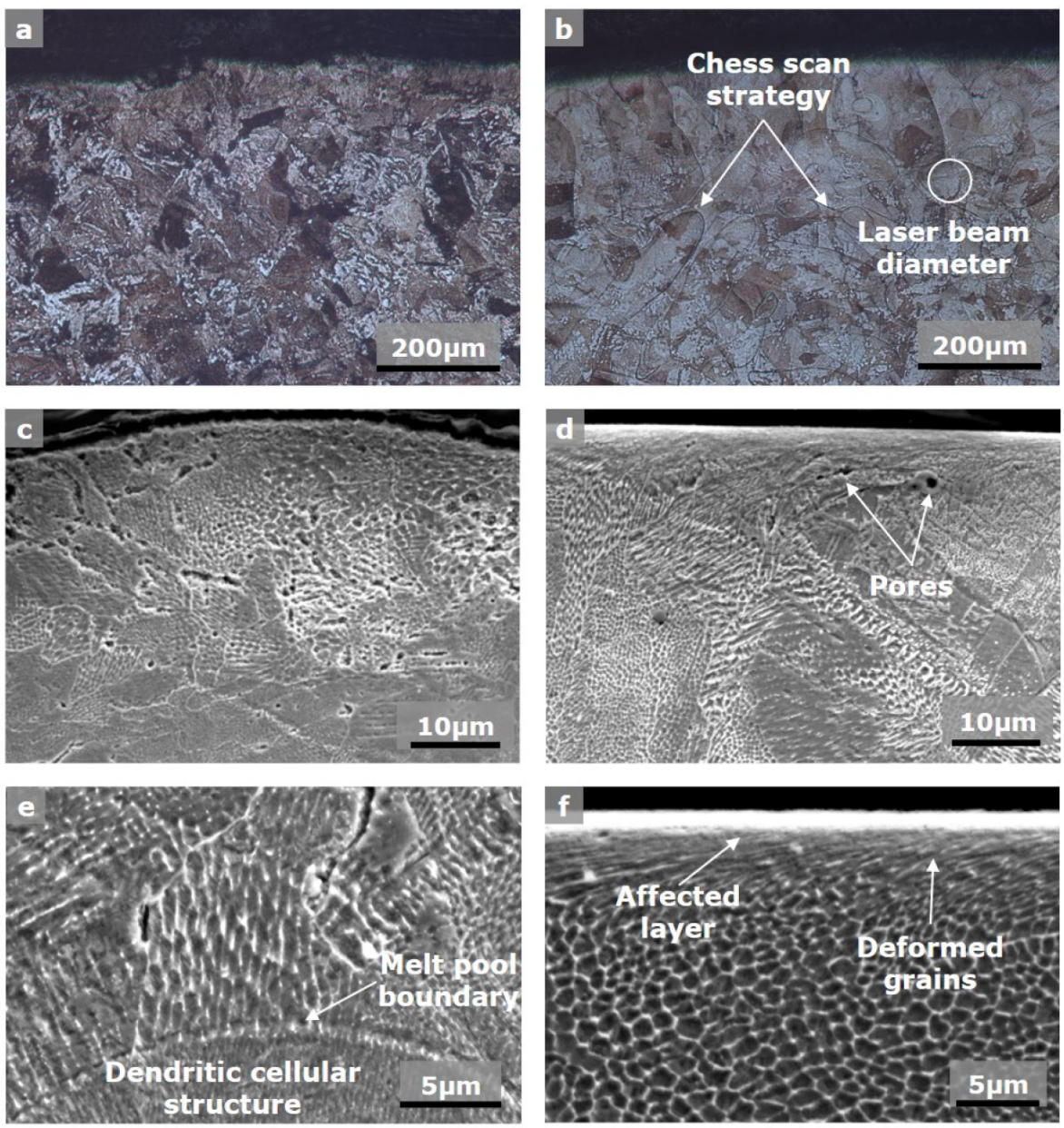

Figure 6. Micrograph of as printed (a, c, e), as burnished samples (b, d, f)

\begin{tabular}{|c|c|c|c|c|}
\hline Specimen & AP & AT & BR & WR \\
\hline HIT $[\mathrm{GPa}]$ & 1.9 & 2.3 & 5.0 & 3.4 \\
\hline
\end{tabular}

Table 2. Surface hardness values for tests on as printed (AP), as turned (AT), as burnished best result (BR) and worst result (WR)

Concerning surface hardness, table 2 displays a substantial increase, especially after burnishing under BR conditions, where hardness HIT increases up to 117\% with respect to sole machining (as turned condition - AT). 
Figure 7 reports the distribution of residual stress in best- and worst-case scenarios, showing that in both cases it is possible to achieve compressive and deep residual stresses.

Thus, the synergy between multiple factors, as addressed earlier, acts in promoting a longer high cycle fatigue life, which is mainly related to the propagation of pre-existing or nucleated defects. High cycle fatigue life increases up to $100 \%$ after burnishing process with respect to the as printed samples, while the sole machining process only introduced a $20 \%$ increase (Figure 8).

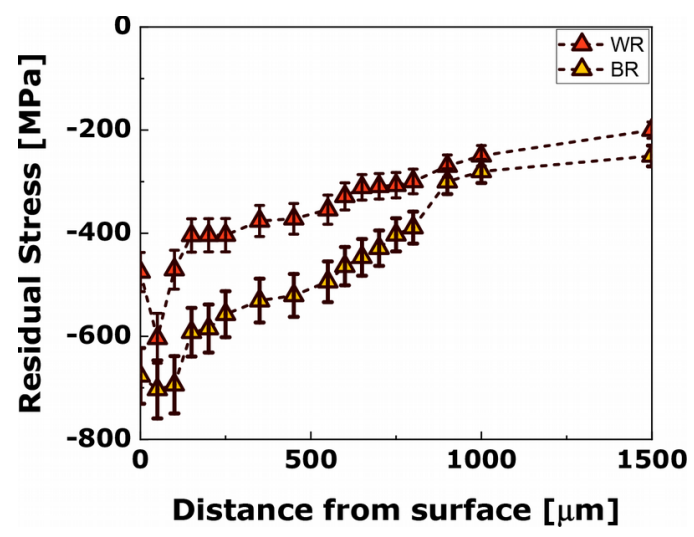

Figure 7. Residual stresses profile for a burnished sample (Sanguedolce et al., 2021)

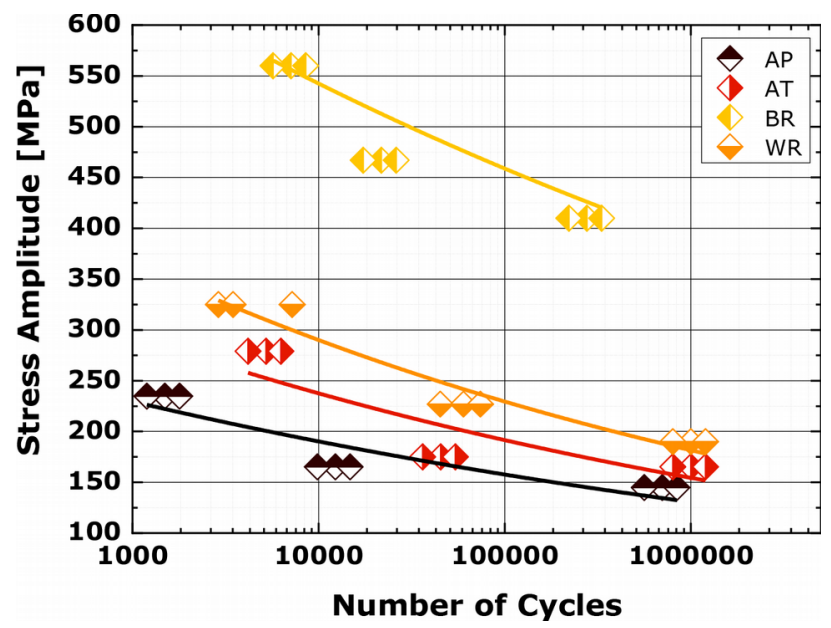

Figure 8. High cycle fatigue life for as printed (AP), as turned (AT), as burnished best result (BR) and worst result (WR) (Sanguedolce et al, 2021)

\section{Conclusions}

The presented study aims to prove the reliability in producing high performance customized products through the developed process chain, which includes the following phases:

- Additive manufactured products creation, which means cost, time and waste reduction;

- Stress relieving process through thermal treatment;

- Turning process to prepare the surface for the burnishing process by removing the low-quality outer layer from the AM process;

- Burnishing superfinishing process leading to improve surface quality and achieve superior product performance. 
The implemented simulation model is useful to predict the final product quality based on the main factors affecting its performance. Furthermore, it contributes to drastically cut down the experimental results needed, leading to a significant reduction of production costs and time. The flexibility of the shown manufacturing line meets the Industry 4.0 specifications maintaining the product quality needed. Concerning the sustainability, the configured chain leads to some implications that should be considered. In particular, it allows avoiding the massive use of metalworking fluids into the involved processes, by reducing the hazards for workers and the environment repercussions, as the amount of generated waste. Also, the costs related to treating waste and safety issues due to machining process and conditions significantly cut down.

The overall results confirm that some of the Industry 4.0 pillars can be successfully integrated into an industrial context to provide product personalization and open new scenarios to companies, allowing the adoption of different technologies, thus extending the optimization area. New generation companies, which already employ compliant technologies with respect to the proposed ones could easily apply such kind of process chain, unlike the traditional ones, which should take into account considerable upgrade costs. Thus, the configuration under investigation is addressed to companies having product customization as a primary purpose.

\section{Declaration of Conflicting Interests}

The authors declare no potential conflicts of interest with respect to the research, authorship and publication of this article.

\section{Funding}

The authors received no financial support for the research, authorship, and publication of this article.

\section{References}

Abdulhameed, O., Al-Ahmari, A., Ameen, W., \& Mian, S.H. (2019). Additive manufacturing: Challenges, trends, and applications. Advances in Mechanical Engineering, 11(2), 1-27. https://doi.org/10.1177/1687814018822880

ASTM E466-15 (2002). Standard Practice for Conducting Force Controlled Constant Amplitude Axial Fatigue Tests of Metallic Materials. Test, 03, 4-8. https://doi.org/10.1520/E0466-07.2

Bai, Q., Wu, B., Qiu, X., Zhang, B., \& Chen, J. (2020). Experimental study on additive/subtractive hybrid manufacturing of 6511 steel: process optimization and machining characteristics. International Journal of Advanced Manufacturing Technology, 108(5-6), 1389-1398. https://doi.org/10.1007/s00170-020-05514-4

Brettel, M., Klein, M., \& Friederichsen, N. (2016). The Relevance of Manufacturing Flexibility in the Context of Industrie 4.0. Procedia CIRP, 41, 105-110. https://doi.org/10.1016/j.procir.2015.12.047

Cao, C., Zhu, J., Tanaka, T., Shiou, F. J., Sawada, S., \& Yoshioka, H. (2019). Ball burnishing of Mg alloy using a newly developed burnishing tool with on-machine force control. International Journal of Automation Technology, 13(5), 619-630. https://doi.org/10.20965/ijat.2019.p0619

De Lacalle, L.N.L., Rodriguez, A., Lamikiz, A., Celaya, A., \& Alberdi, R. (2011). Five-axis machining and burnishing of complex parts for the improvement of surface roughness. Materials and Manufacturing Processes, 26(8), 997-1003. https://doi.org/10.1080/10426914.2010.529589

Delgado, P., Cuesta, I.I., Alegre, J.M., \& Díaz, A. (2016). State of the art of Deep Rolling. Precision Engineering, 46, 1-10. https://doi.org/10.1016/j.precisioneng.2016.05.001

Fera, M., Macchiaroli, R., Fruggiero, F., \& Lambiase, A. (2018). A new perspective for production process analysis using additive manufacturing-complexity vs production volume. International Journal of Advanced Manufacturing Technology, 95(1-4), 673-685. https://doi.org/10.1007/s00170-017-1221-1

Gibson, I., Rosen, D., \& Stucker, B. (2015). Additive Manufacturing Technologies: 3D Printing, Rapid Prototyping, and Direct Digital Manufacturing (2nd ed.). https://doi.org/10.1007/978-1-4939-2113-3 
Gu, X., \& Koren, Y. (2018). Manufacturing system architecture for cost-effective mass-individualization. Manufacturing Letters, 16, 44-48. https://doi.org/10.1016/j.mfglet.2018.04.002

Koren, Y., Shpitalni, M., Gu, P., \& Hu, S.J. (2015). Product design for mass-individualization. Procedia CIRP, 36, 64-71. https://doi.org/10.1016/i.procir.2015.03.050

Lanning, D.B., Nicholas, T., \& Haritos, G.K. (2005). On the use of critical distance theories for the prediction of the high cycle fatigue limit stress in notched Ti-6Al-4V. International Journal of Fatigue, 27(1), 45-57. https://doi.org/10.1016/j.ijfatigue.2004.06.002

Maiß, O., Denkena, B., \& Grove, T. (2016). Hybrid machining of roller bearing inner rings by hard turning and deep rolling. Journal of Materials Processing Technology, 230, 211-216. https://doi.org/10.1016/j.jmatprotec.2015.11.029

Rotella, G., Filice, L., \& Micari, F. (2020). Improving surface integrity of additively manufactured GP1 stainless steel by roller burnishing. CIRP Annals, 69, 513-516. https://doi.org/10.1016/j.cirp.2020.04.015

Salmi, M., Huuki, J., \& Ituarte, I.F. (2017). The ultrasonic burnishing of cobalt-chrome and stainless steel surface made by additive manufacturing. Progress in Additive Manufacturing, 2(1-2), 31-41. https://doi.org/10.1007/s40964-017-0017-z

Sanguedolce, M., Rotella, G., Saffioti, M.R., \& Filice, L. (2021). Functionalized additively manufactured parts for the manufacturing of the future, Procedia Computer Science, 180, 358-365. https://doi.org/10.1016/j.procs.2021.01.174

Schulze, V., Bleicher, F., Groche, P., Guo, Y.B., \& Pyun, Y.S. (2016). Surface modification by machine hammer peening and burnishing. CIRP Annals - Manufacturing Technology, 65(2), 809-832.

https://doi.org/10.1016/j.cirp.2016.05.005

Wang, Y., Ma, H.S., Yang, J.H., \& Wang, K.S. (2017). Industry 4.0: a way from mass customization to mass personalization production. Advances in Manufacturing, 5(4), 311-320. https://doi.org/10.1007/s40436-017-0204-7

Yang, Y., Gong, Y., Qu, S., Rong, Y., Sun, Y., \& Cai, M. (2018). Densification, surface morphology, microstructure and mechanical properties of 316L fabricated by hybrid manufacturing. International Journal of Advanced Manufacturing Tecbnology, 97(5-8), 2687-2696. https://doi.org/10.1007/s00170-018-2144-1

Journal of Industrial Engineering and Management, 2021 (www.jiem.org)

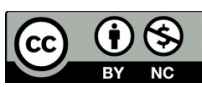

Article's contents are provided on an Attribution-Non Commercial 4.0 Creative commons International License. Readers are allowed to copy, distribute and communicate article's contents, provided the author's and Journal of Industrial Engineering and Management's names are included. It must not be used for commercial purposes. To see the complete license contents, please visit https://creativecommons.org/licenses/by-nc/4.0/. 